\title{
The Dynamics of Disengagement to Departure- An Experience
}

\author{
B. Chandra Mohan Patnaik ${ }^{1}$, Ipseeta Satpathy ${ }^{1} \&$ Chandrabhanu Das ${ }^{1}$ \\ ${ }^{1}$ School of Management, KIIT University, Bhubaneshwar, India \\ Correspondence: B. Chandra Mohan Patnaik, School of Management, KIIT University, Bhubaneshwar, \\ Odisha751024, India. Tel: 91-96-6822-4322. E-mail: bcmpatnaik@gmail.com
}

Received: December 20, $2014 \quad$ Accepted: March 18, $2015 \quad$ Online Published: July 29, 2015
$\begin{aligned} & \text { doi:10.5539/jsd.v8n6p127 } \\ & \text { URL: http://dx.doi.org/10.5539/jsd.v8n6p127 }\end{aligned}$

\begin{abstract}
The present study is an introspection made by the authors to assess the various internal dynamics of disengagement which pave the way for the departure process of an employee from the organizational set up. In this context 223 questionnaires were distributed to the middle level and junior level accounting staffs of 22 private manufacturing units of the capital region of Odisha, India. Sixteen variables were identified through exploratory research and the data was analyzed using Principle Component Analysis (PCA). Thus, the study gives an overview with regards to what determines or what influences people to disassociate themselves with their jobs. It was also found that before leaving a job an employee gives an early signal about their job dissatisfaction, these indications if handled properly, can be helpful in reducing the employee attrition rate.
\end{abstract}

Keywords: disengagement, middle level, junior level, employee

\section{An Overview}

When an individual decides to leave, he doesn't usually wake up one fine morning and spontaneously break the news to his superior. Experts say that the decision is usually triggered after enough consideration. And there are always early signs of disengagement that employers may choose to ignore. It is said that people don't leave companies, they leave bosses. Most employees leave when they believe they have a limited future, cannot stand their boss or feel the organization does not care about the value they bring to the table. To address this issue some companies implemented the 'Stability Meter' as a measurement tool to have access and to keep a check on any early signs of disengagement. It comprises of three colors- green, orange and amber. The employees under orange and amber are ones showing the signs of disengagement and need to be converted to green (happy and satisfied employees). Some organizations have "Early Warning System (EWS)" in place to gauge the preliminary signs of disengagement among employees. Those likely to feel disengaged are detected by the EWS and supported by a Performance Improvement Plan (PIP). The situation may arise due to various reasons. This may be due to bad hiring decision or a person job fit mismatch which will definitely cause that person to feel demotivated. In this direction a candidate must divulge honest information during the interview and HR manager should identify the skills the candidate possess and accordingly assign him job responsibilities. When an employee has skill variety, identifies a piece of his own work and realizes his work has significance for others than only he will experience he will experience the meaningfulness of work. Meaningful consists of skill variety plus task identity and task significance. Positive attitude will lead to organizational citizenship behavior and organizational commitment. Sometimes, bad hiring decisions may lead to employee disengagement in terms of 'post-hire shocks'. Thus, it is vital that the expectations are set right at the beginning.

Disengagement at work is a major concern. However, detecting the early signs can go a long way in retaining talent. After all, you don't want to miss out on employees who get you good returns.

Detachment from engagement of employee is a complicated process and therefore its understanding requires certain academic and administrative knowledge. The research also finds that non-engagement as personal choice (Elena Hekkeri, 2010). The process of employee disengagement appears to be associated with conditions where there is a deficiency of psychological recognition and psychological purpose. Disengagement also appears to be maximizing under condition of inadequate control and when there is lack of confidence between managers and subordinate staff (Richard Pech, Bret Slade, 2006).

Another study was undertaken to identify the relationship among work characteristics satisfaction, morale disengagement and work place misbehavior. As per the findings employees with adverse opinion of their job 
tend to experience negative effect and to rely that it is acceptance to hurt others. The result of the study provides evidence of relationship and several workplace characteristics (Marvin Claybourn, 2011).

The mediating role of morale disengagement and gender in this relationship is consistent with the hypothesis. It was found that individual with greater inclination to face negative emotions were more likely to engage in counterproductive official behavior. When they had higher trial to morally disalign. It was also found that interacting relationship varied across men and women (Al Karim \& S.D. Salman, 2014). The main cause of employee disengagement is poor leadership, where by employees do not have good professional relationships with their manager and are not given the opportunity to communicate and have some control in decision making, let alone receive information from their manager (E. Masiah, V. P. Singh \& M. R. Tirkey, 2013)

\section{Symptoms of Disengagement}

$>$ Disengagement does not happen in a day. Just as building the human capital pool in a company takes a longer period, disengagement happens progressively over weeks and months. Managers are often too busy managing the daily goals to notice gradual progression disengagement in employee. Let's look at some sure shot signals of employee disengagement, which if ignored, cost heavily on the company.

$>$ Performance results of an enthusiastic, sincere employee falls-When you find an enthusiastic, consistent high performer suddenly lagging behind, take this as danger sign. Find out reasons for decline in performance - is it monotony or a bad colleague or dissatisfactory working hours or monetary gain expectation? Take corrective actions before it is too delay.

> Proactive employees become responsive-When you notice your proactive employees becoming responsive, it is better to do a real time check. When employees do not give solutions, look dissatisfied in meetings, move away from initiating for projects, indulge in absenteeism and late-comings, and aim to find out the real cause behind their adverse and careless approach.

\section{Objectives of the Study}

$>$ To understand the various reasons of disengagement.

$>$ To undertake a more in-depth study on this issue in other sectors.

\section{Scope and Period of Study}

The study was undertaken for the various accounting executive staff of middle level and junior level management employees working in selected private manufacturing units in Odisha, India. The period of study was June 2014 to November 2014.

\section{Sampling Process and Research Approach}

In support of the objective of the research there is a primary data collection was done through questionnaire administration method in the field through stratified random sampling and then analysis of data was done. In total 223questions distributed in and around capital region of Odisha and out of that 128 responses received. This includes 93 from junior level accounting staff and remaining from middle level accounting staff of private manufacturing units.

To measure the perception level of the respondents with regard to disengagement, the various variables identified are - When employees see that there is not enough training being given in their work domains, they feel less competitive and hence, tend to stray, Being overlooked for due promotion, Comprehending that there is a mismatch in the promised job profile, Become aware that they may get relocated, Recruiting superior got replaced by a new person they do not approve, Getting informed that the organization is involved in unethical practices ,Facing an occurrence of sensual aggravation or ethnic partiality, Getting informed that they are poorly paid in comparison to employees at the similar position, Being squeezed to make an irrational retraction of personal or family life, Insignificant and irrational use of power, Being deprived of taking a leave for family , A closely associated co-worker resigns or is dismissed, Difference with superiors, Fight with a colleague, A surprisingly poor performance ranking anda marginal increase or no increase of salary. The variables have been identified through exploratory research after discussing the same with the sample target respondents the list of variable are given in the table below. In this regard we have taken 5 point scale and assigned as 5,4,3,2 and 1 for the responses of the respondents "Completely agree", "Agree", "Neutral", "Disagree" and Completely disagree" respectively to capture the data from the target respondents. 
Table 1. List of variables identified through exploratory research

\begin{tabular}{l}
\hline List of variables identified through exploratory research \\
Variable 1: When employees see that there is not enough training being given in their work domains, they feel \\
less competitive and hence, tend to stray \\
Variable 2: Being overlooked for due promotion \\
Variable 3: Comprehending that there is a mismatch in the promised job profile \\
Variable 4: Become aware that they may get relocated \\
Variable 5: Recruiting superior got replaced by a new person they do not approve \\
Variable 6: Getting informed that the organization is involved in unethical practices \\
Variable 7: Facing an occurrence of sensual aggravation or ethnic partiality \\
Variable 8: Getting informed that they are poorly paid in comparison to employees at the similar position \\
Variable 9: Being squeezed to make an irrational retraction of personal or family life \\
Variable 10: Insignificant and irrational use of power \\
Variable 11: Being deprived of taking a leave for family \\
Variable 12: A closely associated co-worker resigns or is dismissed \\
Variable 13: Difference with superiors \\
Variable 14: Fight with a colleague \\
Variable 15: A surprisingly poor performance ranking \\
Variable 16: Marginal increase or no increase of salary
\end{tabular}

For data analysis purpose Principle Component Analysis (PCA) method have been applied to get the desired result.

The main information that we try to build through this method is related to factor loadings. It is a Pearson correlation coefficient of an original variable with a factor. The value of the loading typically ranges from -1 to +1 , where higher value indicates high loading and vice versa. In an ideal situation each variable should have a one single loading, but this may not be the case when dealing with real data. In that situation variables with high loading can be considered, ignoring the lower loading factor. Communalities are another area which provides information about proportion of variability that each factor explains related to one variable.

Under Principle Component Analysis (PCA), the most important decision that a researcher need to take is to how many factors to be considered for conducting the analysis. There are different approaches, viz. Eigen value and Scree Plot.

Eigen value concept is related to 'variance explained' concept of regression analysis which indicates the amount of total variance explained by each factor. The higher the Eigen value of a factor higher is the variance explained by the factor. Before extraction, it is assumed that each of the original variables has an Eigen value $=1$. Therefore, it stands to reason that we would expect any single factor, which is a linear combination of some of the original variables, to exceed the value of 1 . Ideally we would like to take factors with Eigen value $>1$ for analysis purpose.

Another approach to identify the number of factors to be considered for analysis is Scree plot. it is a graphical method where each Eigen values are plotted against their variable numbers in a graph. In the graph $\mathrm{X}$ - axis represents Eigen values and $\mathrm{Y}$ - axis represents variables. The rule is that we will take only those factors where the line diagram shows a bend. Because after that bend successive Eigen value's variation drops suddenly and become flatter. This method is more often use in PCA, when we are running the rotation method.

The rotation is basically a technique with the help of which interpretation of factors become more meaningful. In PCA although it is not mandatory, but it's demand may arise if the initial factor solution without rotation may not give us any meaningful result or if the initial factor may come up with lots of cross loadings. Mainly there are two rotation methods are available, viz. orthogonal rotation and oblique rotation method.

In case of orthogonal rotation method provides us the result which reflects the factors are uncorrelated. It is just opposite of oblique method where factors are correlated with each other. Since, the main objective of factor analysis is to obtain a result where corresponding factors are uncorrelated, that is the reason where most of the time researchers are applying this technique. There are three main techniques are available under this method, viz. varimax, quartimax and equamax. Out of these three methods, varimax is most widely use technique to 
conduct orthogonal rotation.

After the application of PCA method, the next task is to name the variables in such a manner so that basic essence of the variables which are comes under one factor can be identified. Once we complete these steps then we can go for construct validity test to check whether the scale that has been developed can be applied for final study.

For conducting this test, we need to see relevance of the data for conducting factor analysis. The basic statistical criteria which need to be fulfilled for this purpose are as follows:

$\checkmark$ Kaiser-Meyer-Olkin $(\mathrm{KMO})>0.70$, and

$\checkmark$ Bartlett Test of sphericity should be significant

The result of the pilot study under PCA method is shown below. The result has been tested by using SPSS (Version 20).

\section{Analysis of the Data}

\subsection{Reliability Test}

Reliability analysis is a technique which shows that the questionnaire used in the study is reliable or not. To be more specific, its purpose is to judge the internal consistency in terms of responses given by respondents. For a reliable questionnaire normally researcher considers the value of Cronbach's Alpha. If this value is $>0.70$, then we can say that questionnaire is reliable. In the present study the result is shown in the SPSS output table below:

Table 2. Reliability statistics

\begin{tabular}{rr}
\hline Cronbach's Alpha & N of Items \\
\hline .770 & 16 \\
\hline
\end{tabular}

The result shows that the questionnaire used in the study is reliable.

\subsection{Validity Test}

As discussed earlier, to conduct factor analysis, certain conditions related to KMO statistic and Bartlett Test of sphericity should be satisfied. The table below gives us the desired result:

Table 3. KMO and Bartlett's test

\begin{tabular}{|c|c|c|c|}
\hline \multicolumn{3}{|c|}{ Kaiser-Meyer-Olkin Measure of Sampling Adequacy. } & .771 \\
\hline \multirow{3}{*}{$\begin{array}{l}\text { Bartlett's } \\
\text { Sphericity }\end{array}$} & \multirow{3}{*}{ Test } & Approx. Chi-Square & 933.165 \\
\hline & & $\mathrm{df}$ & 120 \\
\hline & & Sig. & .000 \\
\hline
\end{tabular}

The table shows KMO statistic as $0.77(>0.70)$ and Bartlett test sphericity is also significant. This shows that for the present study we can apply factor analysis. In this analysis we have decided to apply PCA method with 3 factor loading and varimax principle to get the desired result. The result is shown as follows:

Table 4. Final variables

\begin{tabular}{|c|c|c|c|c|}
\hline \multirow[t]{2}{*}{ Sl. No. } & \multirow[t]{2}{*}{ Variables } & \multicolumn{2}{|r|}{ Loadings } & \multirow[t]{2}{*}{ Communalities } \\
\hline & & Factor 1 & Factor 2 Factor 3 & \\
\hline 1 & $\begin{array}{l}\text { Variable 6: Getting informed that the } \\
\text { organization is involved in unethical practices }\end{array}$ & 0.740 & & 0.594 \\
\hline 2 & $\begin{array}{l}\text { Variable 8: Getting informed that they are } \\
\text { poorly paid in comparison to employees at the } \\
\text { similar position }\end{array}$ & 0.736 & & 0.694 \\
\hline
\end{tabular}


3 Variable 5: Recruiting superior got replaced by a new person they do not approve

4 Variable 10: Insignificant and irrational use of power

$5 \quad$ Variable 1: When employees see that there is not enough training being given in their work

6 Variable 7: Facing an occurrence of sensual aggravation or ethnic partiality

7 Variable 3: Comprehending that there is a

8 Variable 2: Being overlooked for due promotion

0.636

9 Variable 4: Become aware that they may get relocated

10 Variable 9: Being squeezed to make an

0.616 irrational retraction of personal or family life

11 Variable 14: Fight with a colleague

0.822

0.754

12 Variable 13: Difference with superiors

0.719

13 Variable 11: Being deprived of taking a leave for family

14 Variable 12: A closely associated co-worker resigns or is dismissed

15 Variable 15: A surprisingly poor performance ranking

16 Variable 16: Marginal increase or no increase of salary

$\%$ of Variance Explained

30.23

\subsection{4}

0.707

0.751

0.574

0.716

0.526

Cumulative Variance Explained

$16.14 \quad 9.91$

$56.29 \%$

The table shows that the three factor PCA model can explain $56 \%$ of the total variable explained, which a good result is. The table also shows that each of the component is loaded quite highly with their respective factors and the communalities values shown against each component in the last column is also high (it can be noted that communalities values are all $>0.40$ which is a good result, reflecting that the factors can explain the components). Thus, the result shows that variables $6,8,5,10,1,7,3,2,4,9$ are loaded with factor one which explains $30 \%$ of the total variance explained; variables 14, 13, 11, 12 are loaded with second factor which explains $16 \%$ of the variance explained; and the variables 15 and 16 loaded with third factor which explains $10 \%$ of the variance explained.

Thus, the variables can be broadly categorized under three broad dimensions as follows:

Table 5. Categorization of variables

Variable 6: Getting informed that the organization is involved in unethical practices

Variable 8: Getting informed that they are poorly paid in comparison to employees at the similar position

Disengagement due to low employee friendly policy

Variable 5: Recruiting superior got replaced by a new person they do not approve

Variable 10: Insignificant and irrational use of power

Variable 1: When employees see that there is not enough training being given in their work 
Variable 7: Facing an occurrence of sensual aggravation or ethnic partiality

Variable 3: Comprehending that there is a mismatch in the promised job profile

Variable 2: Being overlooked for due promotion

Variable 4: Become aware that they may get relocated

Variable 9: Being squeezed to make an irrational retraction of personal or family life

\begin{tabular}{lll}
\hline $\begin{array}{l}\text { Disengagement due to } \\
\text { attachment with family } \&\end{array}$ & $\begin{array}{l}\text { Variable 14: Fight with a colleague } \\
\text { co-workers }\end{array}$ & $\begin{array}{l}\text { Variable 13: Difference with superiors } \\
\text { Variable 11: Being deprived of taking a leave for family } \\
\text { Variable 12: A closely associated co-worker resigns or is dismissed }\end{array}$ \\
\hline $\begin{array}{l}\text { Disengagement due to lower } \\
\text { than expected benefits from } \\
\text { company }\end{array}$ & Variable 15: A surprisingly poor performance ranking \\
\hline
\end{tabular}

\section{Conclusion}

The result shows that most of the disengagement happens because of these three broad dimensions mentioned above. People would like to show early trends of discontinuation from the services if they found that policies adopted by the companies are not employee friendly. If the employees learn that the companies are unethical, or they underpaid, lack of training, facility to upgrade skills, sexual racial harassment in the workplace then they try to detach themselves from their present work. Along with that, if the companies are not concerned about the employee's family relations and family bonding then these employees will also try to look for new opportunities. The result clearly shows that if they are not getting leave due to family reasons then, most likely they would like to turnover. Not only that this factor also explains that noncooperation from coworkers and termination of close colleagues also influences their decision to turnover. The third factor obviously related to performance of the employees in the workplace. If the employees failed to get desired level of benefits then it is most likely that they will turnover at the earliest.

Thus, the study gives an overview what determines or what influences people to disassociate themselves with their jobs. As mentioned earlier before leaving a job an employee gives early signal about their job dissatisfaction, these indications if handled properly, then it can reduce the employee attrition rate.

\section{References}

Claybourn, M. (2011).Relationship between moral disengagement, work characteristics and work place harassments. Journal of Business Ethics. http://dx.doi.org/10.1007/s10551-010-0680-1

Hekkeri, E. (2010).Roots and consequences of employee disengagement phenomenon. Master Thesis.

Masiah, E., Singh, V. P., \& Trikey, M. R. (2013). The employee engagement: Engaging employees at work place. International Journal of Management, 4(5), 69-77.

Pech, R., \& Slade, B. (2006). Employee disengagement - is there evidence of growing problem? Hand book of Business Strategy, 7(1), 21-25. http://dx.doi.org/10.1108/10775730610618585

Samnani, A. K., Salmon, S. D., \& Singh, P. (2014).Negative affect and counterproductive workplace behaviorThe moderating role of moral disengagement and gender. Journal of Business ethics. http://dx.doi.org/10.1007/s10551-013-1635-0

\section{Copyrights}

Copyright for this article is retained by the author(s), with first publication rights granted to the journal.

This is an open-access article distributed under the terms and conditions of the Creative Commons Attribution license (http://creativecommons.org/licenses/by/3.0/). 